UCRL-ID-128670

\title{
One-Dimensional, Steady Compressible Flow with Friction Factor and Uniform Heat Flux at the Wall Specified
}

C. S. Landram

October 27, 1997

This is an informal report intended primarily for internal or limited external distribution. The opinions and conclusions stated are those of the author and may or may not be those of the Laboratory. 


\section{DISCLAIMER}

This document was prepared as an account of work sponsored by an agency of the United States Government. Neither the United States Government nor the University of California nor any of their employees, makes any warranty, express or implied, or aseumes any legal liability or responsibility for the accuracy, completeness, or usefulness of any information, apparatus, product, or process disclosed, or represents that its use would not infringe privately owned rights. Reference herein to any specific commercial product, process, or service by trade name, trademark, manufacturer, or otherwise, does not necessarily constitute or imply its endorsement, recommendation, or favoring by the United States Government or the University of California. The views and opinions of authors expressed herein do not necessarily state or reflect thoee of the United States Government or the University of California, and shall not be used for advertising or product endorsement purposes.

This report has been reproduced directly from the best available copy.

Available to DOE and DOE contractors from the Office of Scientific and Technical Information

P.O. Box 62, Oak Ridge, TN 37831

Prices available from (615) 576-8401, FTS 626-8401

Available to the public from the

National Technical Information Service

U.S. Department of Commerce

5285 Port Royal Rd.,

Springfield, VA 22161 


\title{
One-Dimensional, Steady Compressible Flow With Friction Factor and Uniform Heat Flux at the Wall Specified"
}

\author{
Charles S. Landram \\ Mechanical Engineering \\ Lawrence Livermore National Laboratory \\ Livermore, CA 94551
}

\section{INTRODUCTION}

Choking limits and flow variables for one-dimensional, compressible flow in heated passages are important parameters in the design of gas-cooled beam stops and gascooled reactor cores, both usually having helium as the coolant and graphite as the heated wall. Choking lengths are considerably shortened by wall heating, and both the solutions for adiabatic and isothermal flows overpredict these limits. Consequently, an unchoked cooling channel configuration designed on the basis of adiabatic flow may be choked when wall heat transfer is considered.

Subsonic passage flows choke when the exit Mach number approaches unity (isothermal flows are an exception which will not be discussed here). The local Mach number within the passage will increase towards the exit for either of two reasons or a combination of the two. Both reasons are the result of a decrease in gas density with increasing axial position caused either by (1) a frictional pressure drop or (2) an increase in static temperature as a result of wall heat transfer.

General formulations for treating one-dimensional, constant area compressible flows with combined friction and wall flux constant have been described in References 1 and 2. The treatments suffer in two respects: results are omitted for prescribed wall heat flux, and the Reynolds analogy is enforced. The latter shortcoming, which relates heat transfer coefficient to friction factor, is known to work well for hydraulically smooth passages, but over predicts the heat transfer coefficient for rough passages that may be encountered for graphite and other materials. The purpose of this work is to present generalized graphical results to readily permit passage design for monatomic gases, the results including accommodation of any independently specified friction factor, heat transfer coefficient, and wall heat flux. Only constant area passages are considered, and the specified wall heat flux is taken to be uniform.

This work was motivated by the need to determine choking limits in the design of the high energy, helium-cooled graphite beam stop (Reference 3) used for the Accelerator Production of Tritium (APT) program.

\section{FORMULATION}

The gas is assumed to be ideal, satisfying the state equations of Appendix A1, the definitions in Appendix A2, and the empirical laws of Appendix A3. The continuity,

\footnotetext{
"Work performed under the auspices of the US Department of Energy by the Lawrence Livermore National Laboratory under contract No. W-7405-Eng-48.
} 
momentum and energy equations applied to the bulk of the gas at any axial position $x$ measured from the passage inlet, $x=0$, are respectively given by

$$
\begin{gathered}
\dot{\mathrm{m}} / \mathrm{A}=\rho \mathrm{u}=\text { constant } \\
\frac{\mathrm{dp}}{\mathrm{dx}}+4 \mathrm{f} \rho \frac{1}{\mathrm{D}_{\mathrm{h}}} \frac{\mathrm{u}^{2}}{2}=-(\dot{\mathrm{m}} / \mathrm{A}) \frac{\mathrm{du}}{\mathrm{dx}} \\
\frac{\mathrm{dT}_{\mathrm{o}}}{\mathrm{dx}}=\frac{\mathrm{q}_{\mathrm{w}} \operatorname{Per}_{\mathrm{H}}}{\dot{\mathrm{mC}}_{\mathrm{p}}}
\end{gathered}
$$

The symbols used are given in the nomenclature.

In the energy equation (3), the wall heat flux $q_{w}$ is prescribed. Note that the wall temperature does not appear in any of these equations and will not be required for solution of these; rather, its value will be subsequently obtained.

With the relationships of Appendices $A 1$ and $A 2$, the stagnation temperature $T_{0}$ is related to the static temperature $\mathrm{T}$ by the following:

$$
\mathrm{T}_{\mathrm{o}}=(1+\beta) \mathrm{T} \text { and } \beta \equiv\left(\frac{\gamma-1}{2}\right) \mathrm{M}^{2}
$$

where $M$ and $\gamma$ are the local Mach number and specific heat ratio, respectively. Based on the derivation given in Appendix B, the momentum equation (2) can be written in the following form after eliminating the pressure gradient using the state equations and continuity equation (1):

$$
\frac{\left(1+\gamma M^{2}\right)}{2} \frac{1}{T_{0}} \frac{d T}{d x}-\frac{\left(1-\gamma M^{2}\right)}{2 M^{2}(1+\beta)} \frac{d M^{2}}{d x}+4 f \frac{\gamma}{D_{h}} \frac{M^{2}}{2(1+\beta)}=0
$$

Combining the energy equation (3) with equation (4) yields the following:

$$
(1+\beta) \frac{d T}{d x}+\left(\frac{\gamma-1}{2}\right) \frac{T_{0}}{(1+\beta)} \frac{\dot{d} M^{2}}{d x}=\frac{q_{w} P_{H}}{\dot{m} C_{p}}
$$

The static temperature gradient $\mathrm{dT} / \mathrm{dx}$, in the two simultaneous equations (5) and (6), can be eliminated to give a single equation for the dependence of the square of the local Mach, $y=M^{2}$, on a stretched axial dimension $\xi=4 f x / D_{h}$ : 


$$
\frac{d y}{d \xi}=\left[\frac{(1+\gamma y)}{\frac{1}{\varphi}+\xi}+\gamma y\right] \frac{y\left[1+\left(\frac{\gamma-1}{2}\right) y\right]}{(1-y)}
$$

where

$$
\begin{gathered}
\varphi=\frac{K}{M_{1}\left(1+\beta_{1}\right)} \\
K=\frac{4(\gamma-1)}{\gamma 4 f} \frac{q_{w} \frac{\operatorname{Per}_{H}}{\operatorname{Per}_{W}}}{p_{1} c_{1}}
\end{gathered}
$$

In deriving equation (7), the energy equation (3) was integrated to obtain the linear dependence of stagnation temperature on axial (stretched) distance, this operation requiring that the wall heat flux be uniform (independent of $x$ ). The solution to equation (7) was obtained by numerical integration using the fourth-order Runge-Kutta method whose treatment was that of an initial value problem with all properties known at the inlet of the passage. The choking distance $\xi_{\max }$ was obtained as the singular point of equation (7) was approached ( 1 - $y$ in the denominator approaching zero). For $\xi<$ $\xi_{\max }$, the solution of equation (7) gives the local Mach number distribution, $M=y^{0.5}$.

Within the unchoked region, the static temperature distribution is recovered from either equations (5) or (6) since $y=M^{2}$ has been determined. Based on the same procedure used to derive equation (5), the static pressure gradient can also be recovered in terms of the local static temperature and the Mach number, both of which were independently determined. Consequently, the following differential equations for static temperature $\mathrm{T}$ and pressure $p$ were also evaluated by numerical integration having the $y=M^{2}$ distribution known from the solution to equation (7):

$$
\begin{gathered}
\frac{d T}{d \xi}=\frac{T}{(1+\gamma y)}\left[\frac{(1-\gamma y)}{y} \frac{d y}{d \xi}-\gamma y\right] \\
\frac{d p}{d \xi}=\frac{p}{2}\left[\frac{1}{T} \frac{d T}{d \xi}-\frac{1}{y} \frac{d y}{d \xi}\right]
\end{gathered}
$$

It was then a simple matter to evaluate the local sonic speed $c=(\gamma R T)^{0.5}$ and velocity $u$ $=\mathrm{Mc}$ from their definitions and the previous results. All other properties of the gas, such as density, can be evaluated directly (algebraically) using these results and the equations of state in Appendix A1. Now determination of the wall temperature distribution is considered. 
The local heat transfer coefficient $h$ is defined by the ratio of wall heat flux $q_{w}$ to the difference between wall $\mathrm{T}_{\mathrm{w}}$ and adiabatic wall $\mathrm{T}_{\mathrm{aw}}$ temperatures. The local wall temperature with $q_{w}$ specified and $h$ known from correlations is then found from the following:

$$
T_{w}=q_{w} / h+\left[1-\beta\left(1-R_{t}\right)\right] T_{o^{\prime}}
$$

where $T_{0}$ is the known, linearly distributed stagnation temperature obtained from equation (3), $\beta$ is as defined in equation (4) and $R_{t}$ is the recovery factor which is taken as Prandtl raised to the $1 / 3$ power or about 0.88 for most gases. Since $\beta$ and $1-R_{t}$ are both small, the bracketed term in the above is nearly unity, which means the adiabatic wall temperature is very nearly identical to the stagnation temperature.

It should be mentioned that the heat transfer coefficient $h$ appearing in equation $(10)$ can apply to either thermally developing (entrance) or fully-developed flows, and that none of the other previous results depend on the variation of $h$ with axial position. In the fully-developed cases, evaluation of $h$ through standard Nusselt-Reynolds numbers correlations will require some consideration of temperature-dependent property evaluation, namely in axial variations of the dynamic viscosity (in the Reynolds number where the product of density and velocity is constant) and thermal conductivity (in the Nusselt number).

The parameter $\varphi$ appearing in equation (7a) represents the ratio of total heat transfer over any length $L$ to the rate of inlet enthalpy, the ratio normalized by the stretched length $\xi_{\mathrm{L}}=4 \mathrm{f} \mathrm{L} / \mathrm{D}_{\mathrm{h}}$ (the parameter $\varphi$ is independent of $\mathrm{L}$, however). In the gas dynamics formulations that result (equations (7) through (9)), the friction coefficient appears in only the stretched axial coordinate $\xi$ and the parameter $\varphi$. The heat transfer coefficient, which here is independent of friction factor, only appears in equation (10) in obtaining the wall temperature distribution when the wall heat flux is specified. Since in this formulation the friction factor and heat transfer coefficient can be independently assigned, application of the Reynolds analogy has been avoided, and so the results are applicable to any smooth or roughened passage.

\section{RESULTS}

The numerical integration of equations (7) through (9), solved as initial (inlet) value problems, was performed using variable integration step sizes in the independent variable $\xi$. Because equation (1) was imposed into the solution indirectly through its differentiation, the constancy of the product of density and velocity was used as a good test for the accuracy of the numerical determinations. Integration step sizes were varied so that this product varied no more than $1 \%$ for any one integration sweep between inlet and the choked point. Another validation condition that was satisfied was the excellent comparison (within $1 \%$ ) between the adiabatic choking lengths computed for $\mathrm{K}=0$ and those calculated from the exact solution (Ref. 1) that exists for the adiabatic case. In another consistency check, the static temperature distribution obtained by integration of equation (8) was found to be identical to that obtained by integrating equation (3) and using equation (4).

The choking lengths for monatomic gases $(\gamma=5 / 3)$ are presented in Figure 1. These were obtained by assigning both the inlet Mach number and the heat transfer parameter $\mathrm{K}$ for 
each numerical integration between inlet and the choked point. An example calculation on the use of Figure 1 is given in Appendix C. Presentation of companion results for each point of Figure 1 would be too voluminous and would serve little purpose here. Instead, two points on the Figure 1 are chosen to illustrate the effect of heat transfer and friction on the choking lengths.

Consider the two points shown in Figure 1. Each has about the same choking point, namely about $\xi_{\max }=4.1$. One point, point 1 , is on the adiabatic line $K=0$ (all property variations are caused by friction, none by heat transfer) for which case an inlet Mach number of 0.3065 applies (see Figure 1). The other point, point 2, is subjected to significant heat transfer, $\mathrm{K}=0.5$, and the inlet Mach number must be considerably reduced to 0.05 to have the same choking length as point 1 at $\xi_{\max }=4.1$. The axial distributions of velocity, static temperature, static pressure and Mach number for the two points are shown in Figure 2. These are all normalized to their respective inlet values. For the adiabatic case (point 1 ), the pressure drop by friction causes the density to decrease with axial position to about 0.3 of its inlet value, which by equation 1 , then causes the gas to accelerate in velocity to about 3 times its inlet value. For the diabatic case (point 2), wall heat transfer causes the static temperature to rise by a factor of about 30 times its inlet value, this in turn (by the equation of state) causing a comparable decrease in gas density, which then accelerates the gas to over 100 times its inlet velocity. The much larger acceleration for the diabatic case requires it to have a much lower inlet Mach number to maintain the same choking length as has the adiabatic case. 


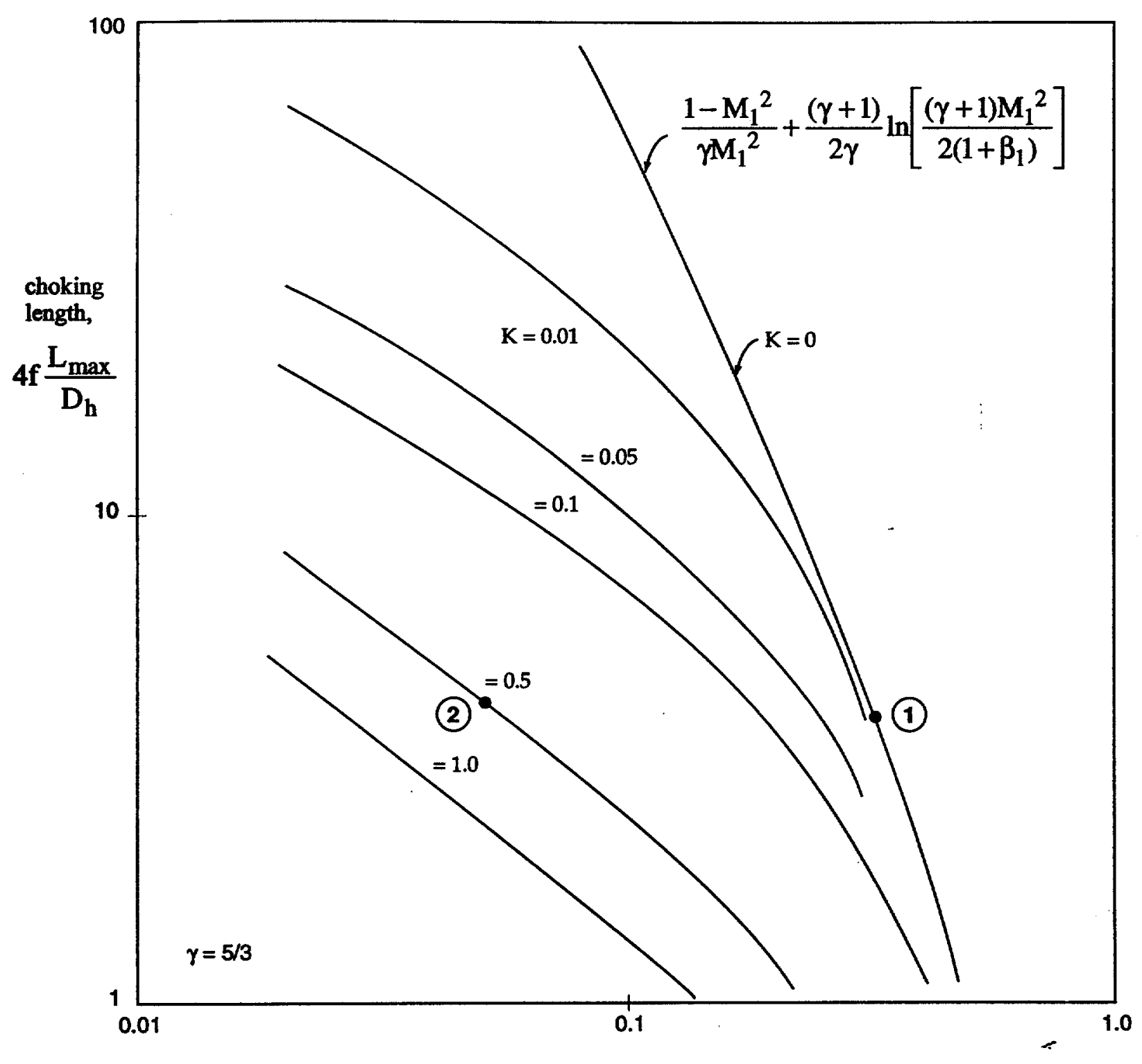

Inlet Mach No. $M_{1}$

Fig. 1 Choking Lengths 


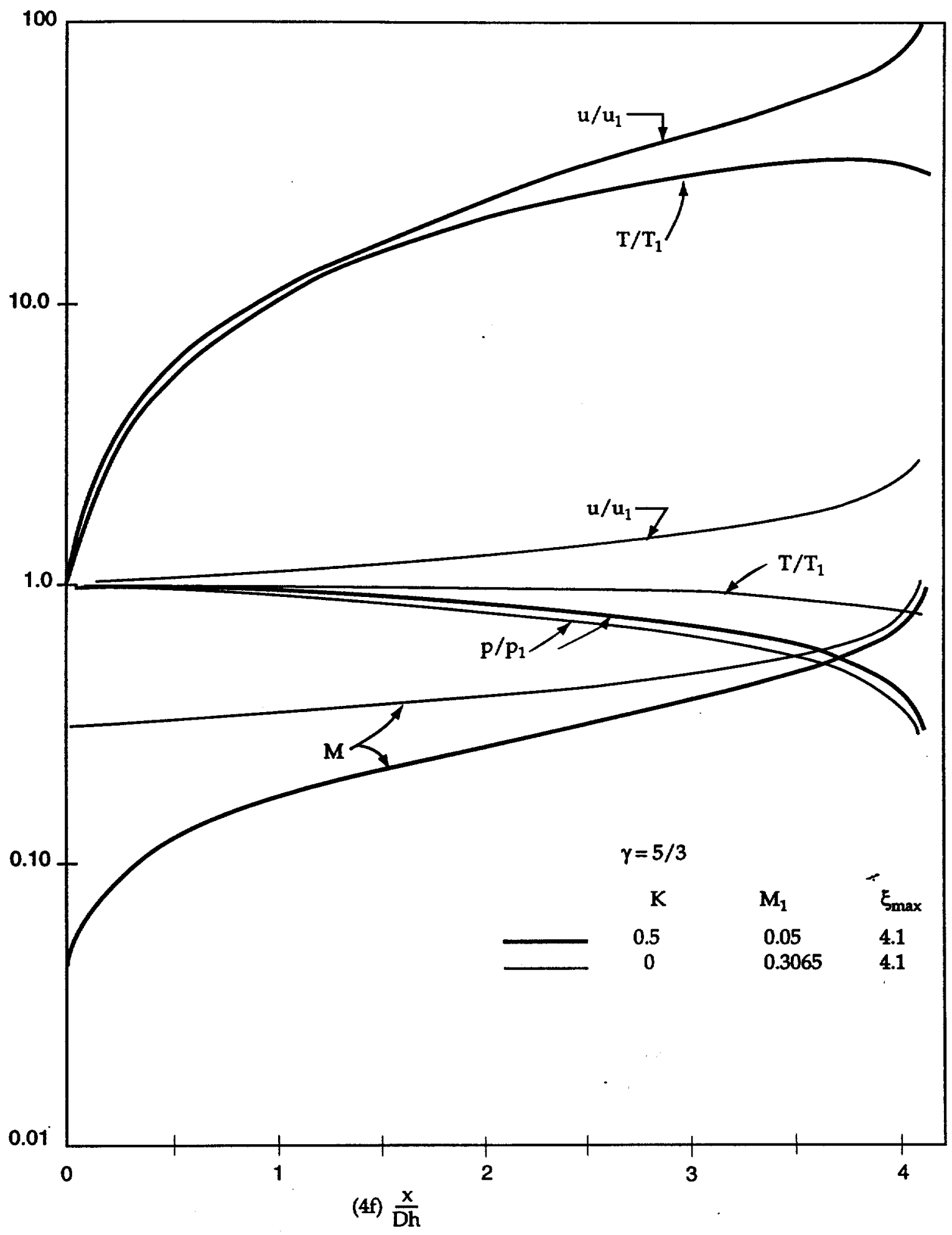

Fig. 2 Axial Profiles 


\section{REFERENCES}

1. Shapiro, Ascher H., The Dynamics and Thermodynamics of Compressible Fluid Flow, Vol 1, The Ronald Press Company, New York, 1953.

2. Daneshyar, H., One-Dimensional Compressible Flow, Pergamon Press, Oxford, 1976.

3. Accelerator Production of Tritium Conceptual Design Report, Draft, LA-UR96-4847, APT-DOC-005, Sect. 5.2.3, Vol. 2, Rev. 1, April 1997. 


\section{APPENDIX A}

Part 1. State Equations (see Nomenclature)

$$
\mathrm{p}=\mathrm{\rho RT}, \quad \mathrm{di}=\mathrm{Cp} \mathrm{dT}, \quad \mathrm{i}=\text { enthalpy }, \quad \mathrm{c}^{2}=\gamma \mathrm{RT}, \quad \mathrm{Cp}=\gamma \mathrm{R} /(\gamma-1)
$$

Part 2. Definitions (see Nomenclature)

$$
M=u / c, \quad T_{o}=T+u^{2} /(2 C p), \quad \beta=(\gamma-1) \frac{M^{2}}{2}, \quad y=M^{2}
$$

\section{Part 3. Empirical} factor 4f:

Wall shear stress which was used in equation (2) is represented by the friction Shear stress $=\rho\left(4 \mathrm{f} \frac{\mathrm{u}^{2}}{2}\right) / 4,4 \mathrm{f}=$ function (Reynolds No., relative roughness) 


\section{APPENDIX B \\ Derivation of equation (5)}

Differentiating the first of Appendix A, Part 1, gives the pressure gradient as

$$
\frac{1}{R} \frac{d p}{d x}=\rho \frac{d T}{d x}+T \frac{d \rho}{d x} \text {. }
$$

Since $p u=$ constant $($ from equation (1)), the density gradient is given by

$$
\frac{d \rho}{d x}=-\frac{\rho}{u} \frac{d u}{d x}
$$

Inserting the last two results into equation (2) and using the defining relations for $c$ and M give

$$
\mathrm{R} \frac{\mathrm{dT}}{\mathrm{dx}}-\left(\frac{1}{\gamma \mathrm{M}^{2}}-1\right) \frac{1}{2} \frac{d \mathrm{u}^{2}}{\mathrm{dx}}+4 \mathrm{f} \frac{1}{\mathrm{D}_{\mathrm{h}}} \frac{\mathrm{u}^{2}}{2}=0
$$

Since

$$
\mathrm{u}^{2}=\gamma \mathrm{RTM}^{2}
$$

we have

$$
\frac{d u^{2}}{d x}=\gamma R\left(T \frac{d M^{2}}{d x}+M^{2} \frac{d T}{d x}\right)
$$

Combining equations (B1) and (B2) gives equation (5) in the text. 


\section{APPENDIX C \\ Example Based on the APT Helium-Cooled High Energy Beam Stop Baseline Design (Reference 3)}

The front module closest to the incoming proton beam has helium cooling slots running through the graphite transverse to the plane of the beam. The graphite absorbs energy deposited by the beam. At the operating beam power, the slots are spaced to give an interfacial gas-to-graphite heat flux of $1.5 \mathrm{MW} / \mathrm{m}^{2}\left(4.74 \times 10^{5} \mathrm{~B} / \mathrm{h} \mathrm{ft} \mathrm{ft}^{2}\right)$. The given inlet gas velocity is $137 \mathrm{~m} / \mathrm{s}(450 \mathrm{ft} / \mathrm{s})$, temperature is $93 \mathrm{C}(200 \mathrm{~F})$, and pressure is 1.03 MPa (150 psia). Since the slot thickness is small $(0.40 \mathrm{~cm})$ compared to the cooling channel width $(23 \mathrm{~cm})$, the hydraulic diameter is approximately $0.80 \mathrm{~cm}$ and Per $_{W}=$ $\operatorname{Per}_{H}$. The friction factor is about $4 \mathrm{f}=0.04$ and the heated length is $20 \mathrm{~cm}$. We need to verify that the heated length is shorter than the choking distance, and we need to find the graphite-helium interface temperature at the exit (end of heated length).

The entering sonic velocity is calculated to be $1126 \mathrm{~m} / \mathrm{s}(3699 \mathrm{ft} / \mathrm{s})$, so that the entering Mach number is $\mathrm{M} 1=137 / 1126=0.122$. The parameter $\beta_{1}=0.005$. The dimensionless heat transfer parameter $\varphi$ is calculated to be 0.418 and $K=0.0512$, these based on the given inlet pressure, friction factor and heat flux. Reference to Figure 1 gives the maximum dimensionless choking length as $\xi_{\max }=8.5$. Therefore

$$
4 \mathrm{f} \frac{L_{\max }}{D_{h}}=8.5
$$

or

$$
\mathrm{L}_{\max }=\frac{0.80(8.5)}{0.04}=170 \mathrm{~cm}
$$

Since $\mathrm{L}=20 \mathrm{~cm}<\mathrm{L}_{\max }=170 \mathrm{~cm}$, the flow is not choked. Note that the adiabatic choking limit at the same inlet Mach number is $\xi_{\max }=35$, giving an adiabatic choking length of $700 \mathrm{~cm}$. In this example, heat transfer reduces the choking length by a factor of about 4, yet the flow remains unchoked.

The exit properties are obtained in this case by integration to the upper limit $\xi_{\mathrm{L}}=1$ corresponding to $\mathrm{L}=20 \mathrm{~cm}$, and these are given in Table $C 1$. The dynamic viscosity and thermal conductivity for helium are evaluated at the static exit temperature of $244 \mathrm{C}$ (471 F). The Reynolds number at the exit, based on the hydraulic diameter of $0.80 \mathrm{~cm}$, is then 54,100. For a Prandtl number of 0.69, the Dittus-Boelter Nusselt number is 124 and so the exit heat transfer coefficient is $3214 \mathrm{~W} / \mathrm{m}^{2} \mathrm{C}\left(568 \mathrm{~B} / \mathrm{hft} \mathrm{f}^{2} \mathrm{~F}\right)$. At the exit the values given in Table C1 allow evaluation of equation (10) for $R_{t}=0.88$ as $T_{w}=711 \mathrm{C}$. For this case, this wall temperature is only about $3 \mathrm{C}$ higher than that calculated as if the flow were incompressible. Compressibility effects will become more important as the heated length approaches the choking length. 
Table C1. Exit properties for example of Appendix C

\begin{tabular}{|l|c|}
\hline Mach number & 0.1490 \\
\hline Static temperature, ${ }^{\circ} \mathrm{C}$ & 244 \\
\hline Stagnation temperature, ${ }^{\circ} \mathrm{C}$ & 248 \\
\hline Static pressure & $0.9736 \mathrm{p} 1$ \\
\hline Velocity & $1.45 \mathrm{u} 1$ \\
\hline Sound speed & $1.19 \mathrm{c} 1$ \\
\hline \multicolumn{2}{|c|}{$\begin{array}{c}\text { p1, u1, and c1 are the given inlet pressure, } \\
\text { velocity, and sound speed, respectively) }\end{array}$} \\
\hline
\end{tabular}




\section{NOMENCLATURE}

$$
\begin{aligned}
& \mathrm{A}=\text { cross-sectional passage flow area } \\
& \text { C = sonic velocity } \\
& C_{p}=\text { gas specific heat at constant pressure } \\
& D_{h} \text { - hydraulic diameter }=4 \mathrm{~A} / \text { Perw } \\
& 4 \mathrm{f}=\text { friction factor defined by eq. (A3) } \\
& \mathrm{h}=\text { heat transfer coefficient } \\
& \mathrm{K}=\mathrm{eq} \cdot(7 \mathrm{~b}) \\
& \dot{\mathrm{m}}=\text { mass rate of flow through passage } \\
& \mathrm{M}=\text { local Mach number }=\mathrm{u} / \mathrm{c} \\
& \mathrm{p}=\text { local static gas pressure } \\
& \operatorname{Per}_{H}=\text { heated periphery of passage at any axial position } \\
& \operatorname{Per}_{\mathbf{w}}=\text { wetted perimeter } \\
& \mathrm{q}_{\mathrm{w}}=\text { specified wall heat flux } \\
& R \quad=\text { gas constant } \\
& \mathbf{R}_{\mathrm{t}} \quad=\text { recovery factor } \\
& \mathrm{T}=\text { local static gas temperature } \\
& \mathrm{T}_{\mathrm{o}}=\text { local stagnation gas temperature } \\
& \mathbf{u}=\text { local gas velocity } \\
& x=\text { axial distance measured from inlet } \\
& y=M^{2} \\
& \beta \quad=\text { defined by eq. (4) } \\
& \rho=\text { local gas density } \\
& \gamma=\text { specific heat ratio }=5 / 3 \text { for a monatomic gas } \\
& \xi \quad=\text { stretched axial distance }=4 \mathrm{f} \frac{\mathrm{x}}{D_{h}} \\
& \varphi=\text { defined by eq. (7a) }
\end{aligned}
$$

$$
\text { Subscripts: } \begin{aligned}
1 & =\text { inlet just inside passage } \\
\text { aw } & =\text { adiabatic wall } \\
0 & =\text { stagnation property } \\
\max & =\text { at the choking length }
\end{aligned}
$$




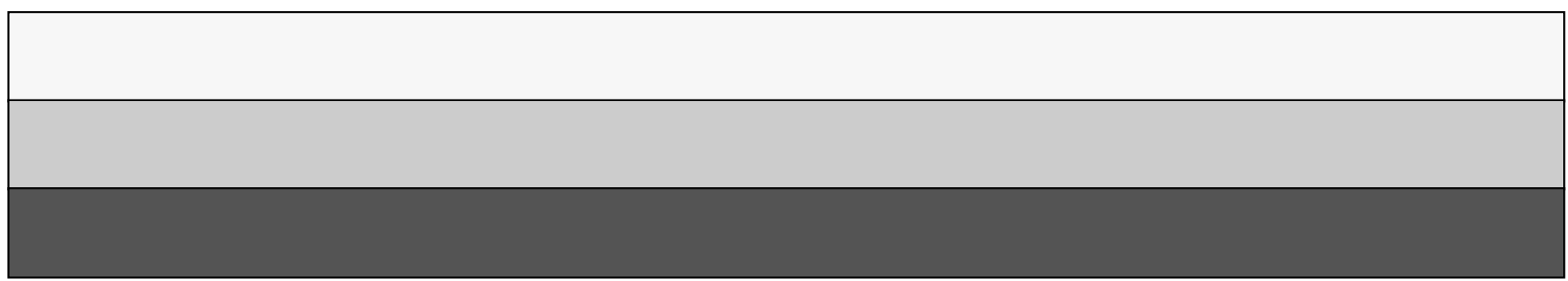

